\title{
ENGINEERING STUDIES ON THE PERFORMANCE OF PADDY AND RICE SEPARATOR
}

\author{
T.Z. Fouda*
}

\section{ABSTRACT}

The performance of paddy and rice separator was theoretically and experimentally investigated as a function of change in separator sieve angle, paddy moisture content and feeding ratios. The separator performance was evaluated in terms of separator productivity, crack percentage, separator efficiency and energy requirements. The theoretical analyses reveal that the optimum sieve speed of $0.5 \mathrm{~m} / \mathrm{sec}$. (200 rpm) is recommended to prevent riding of material on the sieve surface. The experimental results reveal that the separator performance was in the optimum region under the following conditions:

- Sieve angle of $15 \mathrm{deg}$.

- Paddy moisture content of $14 \%$.

- Feeding ratio of 0.80

\section{INTRODUCTION}

gricultural policy depends on the successful technology
through mechanizing the agricultural processes of
strategically crops .One of the most important economical crops is rice as it participates in the international income added to the local consumption in feeding and industrial aspects. So, increasing yield by means of up to date technology through the different stages of rice production is an important question to be answered. One of these stages is rice milling. Major operations carried out in a modern rice mill are cleaning, husking, separation of paddy and rice, whitening and grading. Separation of paddy and rice on the oscillating type separator takes place due to the difference in specific gravity and surface characteristics of paddy and rice. The separating machine separates the product of the husking operation into three parts: brown rice, paddy and a mixture of the two. Brown rice is fed to the whitening machine, paddy is sent back for husking and the mixture is returned to the separator.

* Assoc. Prof. of Agric. Eng., Fac. of Agric. Tanta Un. 
El-Raie (1987) studied the technical parameters of flat sieve such as dimensions of sieve, the speed of crankshaft of screening unit, ideal distribution of the holes on the sieve sheet. These information are very important in designing and developing the specific machines suitable for Egypt. Ahmed (1988) mentioned that the slope of the separating sieve is a controlling factor of the effectiveness of separation. This effectiveness improves significantly as the sieve is also a controlling factor in determining the maximum possible feed rates to the winnowing machine. As the sieve slope increases, the maximum possible feed rates, provided the other factors are kept the same, is greatly reduced. He also found that the maximum values of efficiency of separation is quite different depending on the number of oscillations per minute used. Ahmed et al. (1993) developed a winnowing machine. This machine was designed in such a way to change the parameters affecting the separation effectiveness such as the sieve oscillation, amplitude, sieve angle and feed rate for using a threshed wheat crop by the locally made stationary thresher.

They added that, the separation effectiveness of $97 \%$ was obtained at sieve oscillations of $500 \mathrm{cycle} / \mathrm{min}$, sieve angle of $2 \mathrm{deg}$. and feed rate of $30 \mathrm{~kg} / \mathrm{h} . \mathrm{cm}$. at grain/straw ratio of 1:3.

Amin (2003) studied some engineering parameters affecting cleaning and separating efficiency such as type of motions (vibrating or rotary speeds ), cells shape ( rectangular, square and circle ), position of rectangular cell (parallel or perpendicular with speed direction), sieves inclination and sieving time were considered for each machines type (vibratory and rotary machines). He found that the efficiency increased by increasing sieving time, oscillating and rotary speed. Awady et al. (2003) developed and tested a separating and cleaning machine to winnowing rice crop for better efficiency and reduced losses. The cleaning machine consists of frame, grain hopper, oscillating dual-screen assembly, a centrifugal blower and electric motor. The eccentric and support linkages of screen assembly cause it to oscillate, moving the grain over the flat screen. During the operation, grain is loaded onto the hopper and fed into the oscillating screen through the bottom opening and regulated by the slide gate. 
The upper screen separates the impurities that are bigger than the grain, and the lower screen separates those that are smaller and dust. El-Sahrigi et al., (2004) designed and constructed a separating and cleaning unit able to various types of medicinal and aromatic seeds and their associated foreign matter by making simple adjustments according to the type of seeds, its physical properties and associated impurities. They also tested the performance of a cleaning unit under the following main factors: the frequency of the sieve unit, feed rate, air velocity and slope of the sieve unit. The maximum seed cleanliness and separation effectiveness were 99.01 and $89.75 \%$ respectively and obtained at frequency of $10.50 \mathrm{HZ}$, feed rate of $300 \mathrm{~kg} / \mathrm{h}$, slope of $13 \mathrm{deg}$. And air velocity of $3.2 \mathrm{~m} / \mathrm{s}$.

This research will cover theoretical and experimental analyses of some engineering and operational parameters affecting the performance of paddy and rice separator for the purpose of maximizing separator efficiency and minimizing energy requirements.

\section{MATERIALS AND METHODS}

The main experiments were carried out at Zagazig Milling Company, Sharkia province to study the effect of some engineering and operating parameters on the performance of paddy and rice separator.

\section{- The used crop}

Rice Giza 172 ( short grain ) variety was used

physical and mechanical properties of paddy and brown rice are tabulated in table(1)

Table (1): physical and mechanical properties of paddy and brown rice

\begin{tabular}{|c|c|c|c|c|c|c|c|}
\hline 류.ర. & 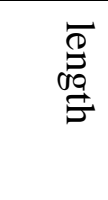 & 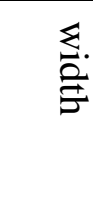 & 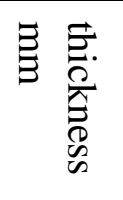 & 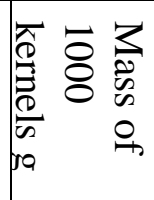 & 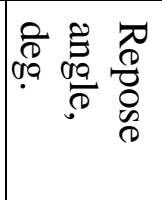 & 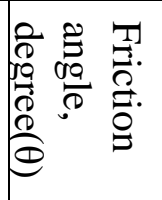 & 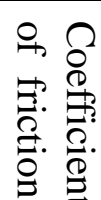 \\
\hline Paddy & 7.70 & 3.22 & 2.45 & 24.90 & $40-45$ & 48 & 1.11 \\
\hline Brown & 5.57 & 2.92 & 2.25 & 21.40 & $33-38$ & 40 & 0.84 \\
\hline
\end{tabular}

\section{- The used separator}

The new SATAKE paddy separator Ps 120E was used with the following specifications: 
- out put capacity : long grains $5.2-5.6$ ton/h

: short grains $6.0-7.2$ ton $/ \mathrm{h}$

- Required power : $0.75 \mathrm{~kW}$

SATAKE new paddy separator is shown in fig. 1.

\section{- The used instruments}

- Repose angle meter was used for measuring the angle between the base and the slope of the grains.

- Digital instrument was used for measuring the friction angle of the grains on metal sheet surface with an accuracy of 0.01 degree.

- Electric digital balance was used for measuring the mass of grains samples with an accuracy of $0.1 \mathrm{mg}$.

-Digital power meter was used to measure the required power for operating the separator.
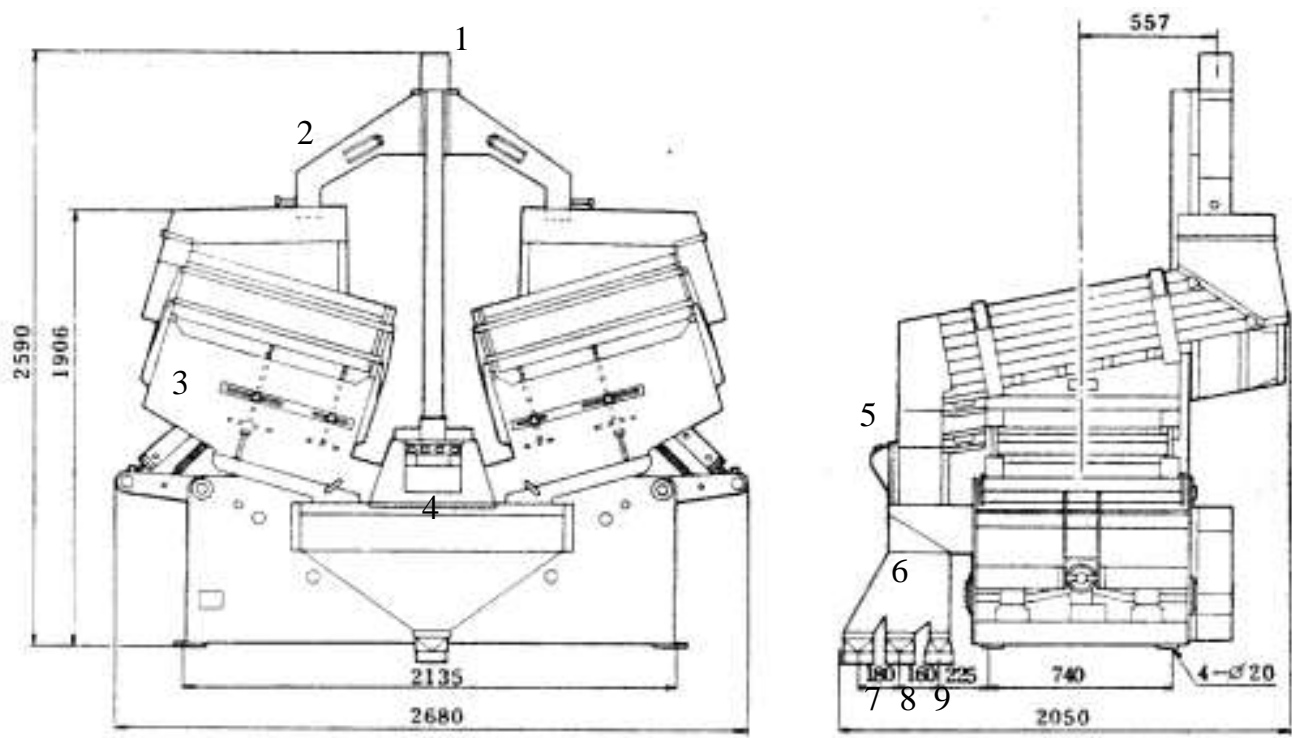

1-Shutter 2-Distributor box 3-Divider plate 4-Switch valve 5-Inclination switch 6-Outlet 7-Brown rice 8-Mixture 9-Paddy Fig. 1: paddy and rice separator

\section{- Separator adjustment}

A vibrated sieve is used to remove paddy from brown rice. Agitation of the separating sieve results in displacement of the paddy and rice over its surface. The paddy and rice should be so agitated that 
separation is optimal. The paddy and rice should be uniformly distributed over the sieve surface and moved towards the delivery end of the sieve. The sieve is agitated by multiple system linkage kinematics characteristics of linear motion of the driving link and the crank-connecting rod mechanism for small values of $\mathrm{r} / \mathrm{L}$ (crank shaft length / connecting rod length) are given by the following ( klenin et al, 1985):

$X=r(1-\cos \omega t)$

$\dot{\mathrm{X}}=\omega \mathrm{r} \sin \omega \mathrm{t}$

$\ddot{\mathrm{X}}=\omega^{2} \mathrm{r} \cos \omega \mathrm{t}$

Where X - Instantaneous displacement , cm

$\dot{X}-$ Motion velocity, $\mathrm{cm} / \mathrm{s}$

$\ddot{\mathrm{X}}$ - Acceleration of motion, $\mathrm{cm} / \mathrm{s}^{2}$

$\omega$ - Angular velocity, $\mathrm{rad} / \mathrm{s}$

$\mathrm{r}-$ crank shaft length, $\mathrm{cm}$

The following forces acting paddy and rice lying on a sieve:

1- W : Force due to the weight of the paddy and rice directed downward.

2- $\mathrm{F}_{\mathrm{i}}$ : Inertia force acting in a direction opposite to that of the mass acceleration force. The magnitude of the force $F_{i}$ is obtained as follows:

$\mathrm{F}_{\mathrm{i}}=\mathrm{m} \ddot{\mathrm{X}}=\mathrm{m} \omega^{2} \mathrm{r} \cos \omega \mathrm{t}$

Where $\mathrm{m}$ - mass of paddy and rice

3- $F_{f}$ : Friction force between the paddy and rice and the sieve surface acting in a direction opposite to motion direction.

4- $\mathrm{R}$ : Reaction force of the working surface on the rice acting in a direction normal to the surface.

The sieve is set horizontal or inclined to the horizontal plane, the angle of inclination selected from the condition

$\alpha \leq \phi$

where $\alpha$ : Angle of sieve with the horizontal

$\phi$ : The friction angle between the mixture and the sieve surface .

According to the condition given above, the material will not slide over the sieve when it is stationary. When the sieve is agitated at a 
particular frequency and amplitude, a motion is imported to the material relative to the sieve surface.

The possible types of motion of the material are only sliding motion over the sieve towards the delivery end, and in the reverse direction or loss of all contact between the material and the sieve surface.

-Motion of material over the sieve surface at the delivery end from A to $B$

Motion at the delivery end is possible when the resultant of all forces acting the material is greater than the friction force (fig.2) that is :

$$
\begin{gathered}
\mathrm{W} \sin \alpha+\mathrm{F}_{1} \cdot \cos \alpha \geq \mathrm{F}_{\mathrm{f}} \\
\mathrm{F}_{\mathrm{f}}=\mathrm{R} \tan \phi=\mu \mathrm{R}
\end{gathered}
$$

When $F_{f}$ : the friction force

$$
\begin{aligned}
& \phi: \text { friction angle } \\
& \mu: \text { coefficient of friction } \\
& R: \text { normal force }
\end{aligned}
$$

To determine force $\mathrm{R}$ projecting all the forces in a direction normal to the sieve.

$\mathrm{R}=\mathrm{W} \cos \alpha-\mathrm{F}_{\mathrm{i}} \sin \alpha$

Then motion of the seed at the exit may be expressed by the following inequality:

$\mathrm{W} \sin \alpha+\mathrm{F}_{\mathrm{i}} \cos \alpha \geq \mu \mathrm{W} \cos \alpha-\mu \mathrm{F}_{\mathrm{i}} \sin \alpha$. or $\mathrm{mg} \sin \alpha+\mathrm{m} \omega^{2} \mathrm{r} \cos \alpha \geq \mu \mathrm{mg} \cos \alpha-\mu \mathrm{m} \omega^{2} \mathrm{r} \sin \alpha$

or

$$
\begin{array}{rlr}
\omega_{1} & =\sqrt{\frac{\mathrm{g}(\mu \cos \alpha-\sin \alpha}{\mathrm{r}(\cos \alpha+\mu \sin \alpha)}} \quad \mathrm{rad} / \mathrm{s} \\
\mathrm{N}_{1} & =\frac{60}{2 \pi} \sqrt{\frac{\mathrm{g}(\mu \cos \alpha-\sin \alpha)}{\mathrm{r}(\cos \alpha+\mu \sin \alpha)}} \quad \mathrm{rpm}
\end{array}
$$

Sliding motion of the material up and down the sieve surface from B to $A$

Fig. 3 show the movement of material from $\mathrm{B}$ to $\mathrm{A}$ is possible when:

$\mathrm{F}_{\mathrm{i}} \cos \alpha-\mathrm{W} \sin \alpha \geq \mathrm{F}_{\mathrm{f}}$

Where $\mathrm{R}=\mathrm{W} \cos \alpha+\mathrm{F}_{1} \sin \alpha$

Then the motion of material in this cos e may be expressed by the following inequality :

$\mathrm{F}_{\mathrm{i}} \cos \alpha-\mathrm{W} \sin \alpha \geq \mu \mathrm{W} \cos \alpha+\mu \mathrm{F}_{\mathrm{i}} \sin \alpha$

$\mathrm{m} \omega^{2} \mathrm{r} \cos \alpha-\mathrm{mg} \sin \alpha \geq \mu \mathrm{mg} \cos \alpha+\mu \mathrm{m} \quad \omega^{2} \mathrm{r} \sin \alpha$

$$
\omega_{2}=\sqrt{\frac{g(\mu \cos \alpha+\sin \alpha}{\mathrm{r}(\cos \alpha-\mu \sin \alpha}} \quad, \mathrm{rad} / \mathrm{s}
$$




$$
\mathrm{N}_{2}=\frac{60}{2 \pi} \sqrt{\frac{\mathrm{g}(\mu \cos \alpha+\sin \alpha)}{\mathrm{r}(\cos \alpha-\mu \sin \alpha)}} \quad, \mathrm{rpm}
$$

\section{Riding of material on the sieve surface}

The motion of material in this case may be expressed by the following inequality :

$$
\mathrm{W} \sin \alpha+\mathrm{F}_{\mathrm{i}} \cos \alpha \geq \mathrm{F}_{\mathrm{f}}
$$

But in this case $\mathrm{R}=0$

$$
\therefore \mathrm{F}_{\mathrm{f}}=0
$$

$\mathrm{F}_{\mathrm{i}} \cos \alpha \geq-\mathrm{W} \sin \alpha$

$m \omega^{2} r \cos \alpha \geq-m g \sin \alpha$

$$
\begin{aligned}
& \omega_{3}=\sqrt{\frac{-\mathrm{g} \sin \alpha}{\mathrm{r} \cos \alpha}}, \mathrm{rad} / \mathrm{s} \\
& \mathrm{N}_{3}=\frac{60}{2 \pi} \sqrt{\frac{-\mathrm{g} \sin \alpha}{\mathrm{r} \cos \alpha}}, \mathrm{rpm}
\end{aligned}
$$

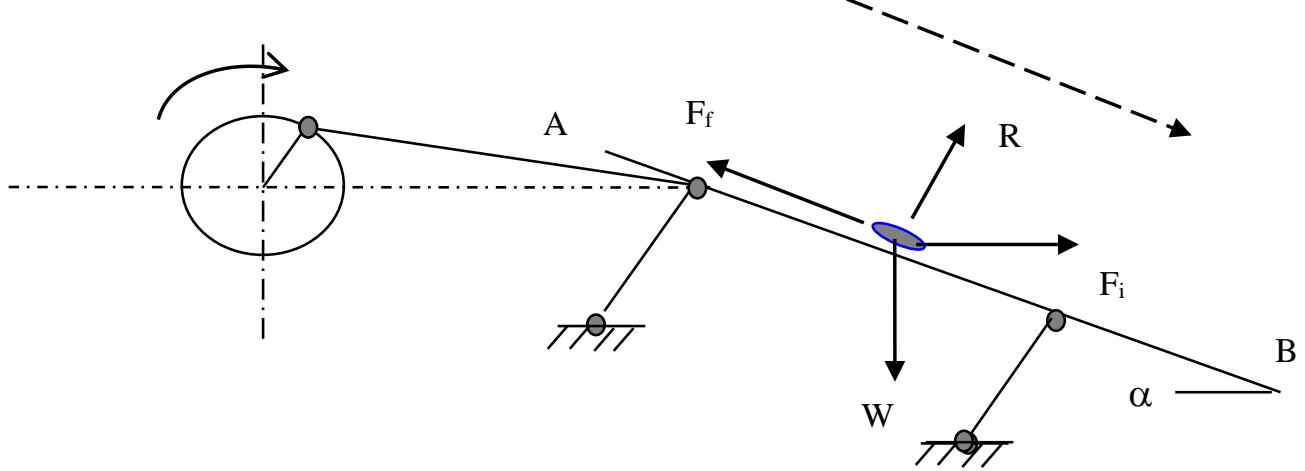

Fig. 2 : Motion of material over the sieve surface at the delivery end from $\mathrm{A}$ to $\mathrm{B}$

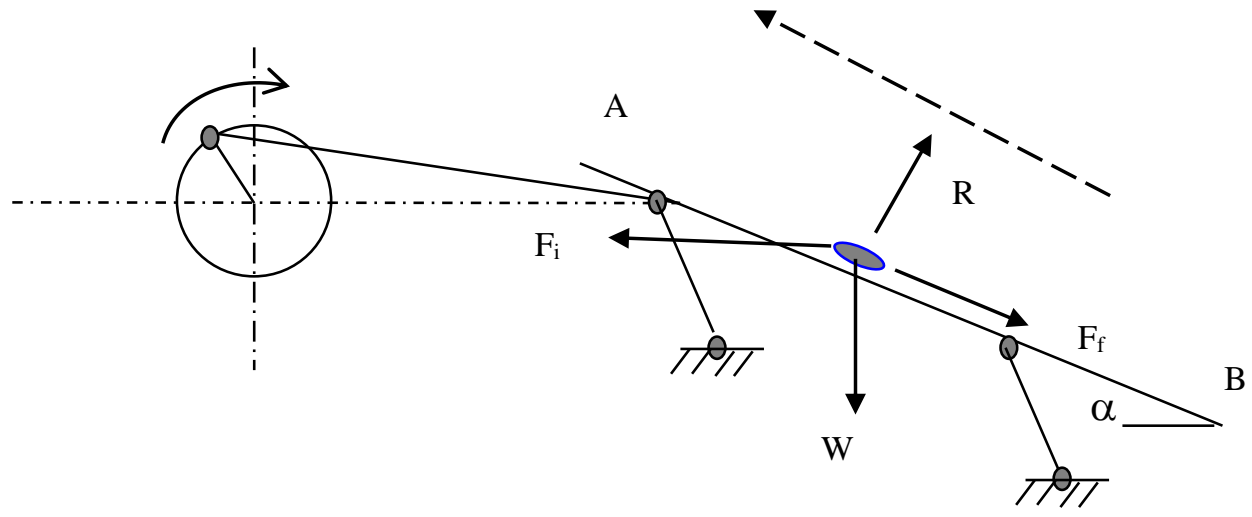

Misr J. Ag. Eng., April 2009 
Fig. 3 : Sliding motion of the material up and down the sieve surface from $\mathrm{B}$ to $\mathrm{A}$

It follows from these equations that the mass of material moves a long the sieve to ward the exit $\left(\mathrm{N}>\mathrm{N}_{1}\right)$ and to the opposite direction $(\mathrm{N}>$ $\mathrm{N}_{2}$ )

Sieving and separating are more successful under the following conditions:

$$
\mathrm{N}_{3}>\mathrm{N}>\mathrm{N}_{2} \text { and } \mathrm{N}_{2}>\mathrm{N}_{1}
$$

Where $\mathrm{N}$ : the optimum sieve speed

Under the above conditions and by using the previous equations the separator was adjusted as follows:

- Angle of sieve with the horizontal is determined to be less than the friction angle between the material and the sieve surface $\alpha \leq \phi$

$\therefore \alpha \leq 40 \mathrm{deg}$.

- Optimum sieve speed was calculated to be as follows:

$\mathrm{N}=200 \mathrm{rpm}=(3.33 \mathrm{HZ})$ corresponding to an linear sieve speed of $0.5 \mathrm{~m} / \mathrm{s}$

\section{- Experimental procedures}

Experiments were carried out to study the effect of the following parameters on the performance of paddy and rice separator:

- Four different sieve angles with the horizontal (10, 12, 15 and 20 deg.)

-Four different paddy moisture contents ( 10, 12, 14 and 16\%).

- Five different feeding ratios $(0.50,0.60,0.70,0.80$, and 0.90$)$.

The feeding rate ratios was calculated as follows:

$$
\text { Feeding rate ratio }=\frac{\mathrm{Q}}{\mathrm{Q}_{\max }}
$$

Where $\mathrm{Q}$ : the actual feeding rate

$\mathrm{Q}_{\max }$ : the maximum feeding rate $(7200 \mathrm{~kg} / \mathrm{h}$.)

\section{Measurements}

\section{Separator productivity:}

Separator productivity was calculated as follows:

$$
\text { Separator productivity }(\mathrm{Mg} / \mathrm{h})=\frac{\mathrm{Q}}{\mathrm{t}}
$$


Where Q: mass of brown rice sample, $\mathrm{Mg}$.

$\mathrm{t}$ : time consumed in separating operation, $\mathrm{h}$.

\section{Crack percentage:}

crack percentage was calculated as follows:

$$
\text { Crack percentage, } \%=\frac{\mathrm{C}}{\mathrm{T}} \times 100
$$

Where C: mass of cracked in brown rice sample, $\mathrm{g}$.

$\mathrm{T}$ : mass of the total sample, $\mathrm{g}$.

\section{Separator efficiency :}

The paddy and rice separator efficiency was measured using the following equation

\section{( Modi 1972)}

$$
\zeta \mathrm{s}=\frac{\mathrm{x}_{\mathrm{b}}\left(\mathrm{x}_{\mathrm{s}}-\mathrm{x}_{\mathrm{p}}\right)\left(\mathrm{x}_{\mathrm{b}}-\mathrm{x}_{\mathrm{s}}\right)\left(1-\mathrm{x}_{\mathrm{p}}\right)}{\mathrm{x}_{\mathrm{s}}\left(1-\mathrm{x}_{\mathrm{s}}\right)\left(\mathrm{x}_{\mathrm{b}}-\mathrm{x}_{\mathrm{p}}\right)^{2}}
$$

Where $\mathrm{x}_{\mathrm{b}}$ - Weight of brown rice fraction in the collection from the brown rice outlet of the separator;

$\mathrm{x}_{\mathrm{p}}$ - Weight of brown rice fraction in the collection from the paddy outlet of the separator;

$\mathrm{x}_{\mathrm{s}}$ - Weight of brown rice fraction in the sum of the collection from the brown rice outlet and paddy outlet of the separator.

\section{Energy requirements:}

Energy requirements was calculated using the following equation:

Energy requirements, W.h/Mg= Required power(W)

The required power was measured using the digrital power meter

\section{RESULTS AND DISCUSSION}

The obtained results will be discussed under the following items

\section{- Factors affecting separator productivity.}

Separator productivity is significantly affected by sieve angle, paddy moisture content and feeding ratio.

Relating to the effect of sieve angle on separator productivity, results in fig. 4 show that increasing sieve angle from 10 to 15 degrees, measured for various feeding ratios of $0.5,0.6,0.7,0.8$ and 0.9 , increased separator productivity by $16.02,16.29,37.01,38.34$ and $29.78 \%$ at constant paddy moisture content of $14 \%$. Any further 
increase in sieve angle from 15 up to 20 degrees, separator productivity was decreased by $3.84,7.07,24.53,24.47$ and $17.20 \%$ under the same previous conditions. The increase in productivity by increasing sieve angle from 10 to $15 \mathrm{deg}$. Is attributed to the uniform sliding of brown rice towards brown rice out let. While the decrease in productivity by increasing sieve angle from 15 to $20 \mathrm{deg}$. Is attributed the fast sliding of brown rice towards paddy entrance.

Regarding the effect of paddy moisture content on separator productivity, obtained data in fig.5 show that increasing moisture content from 10 to $16 \%$, measured at various separator ratios of 0.5 , $0.6,0.7,0.8$ and 0.9 , decreased separator productivity by $11.76,13.53$, $13.41,4.53$ and $3.15 \%$ at constant sieve angle of 15 degree. This is due to the heavy weight of high moisture content material which causes brown rice to fall into the out let of paddy and mixture.

As to the effect of feeding ratio on separator productivity, results in figs. 4 and 5 show that increasing feeding ratio from 0.5 to 0.9 increased separator productivity by $68.54 \%$ at constant paddy moisture content of $14 \%$ and constant sieve angle of 15 degree. This can be explained by the fact that when feeding ratio increased, material covers the surface of the sieve uniformly which gives smooth movement of materials towards their outlets. 


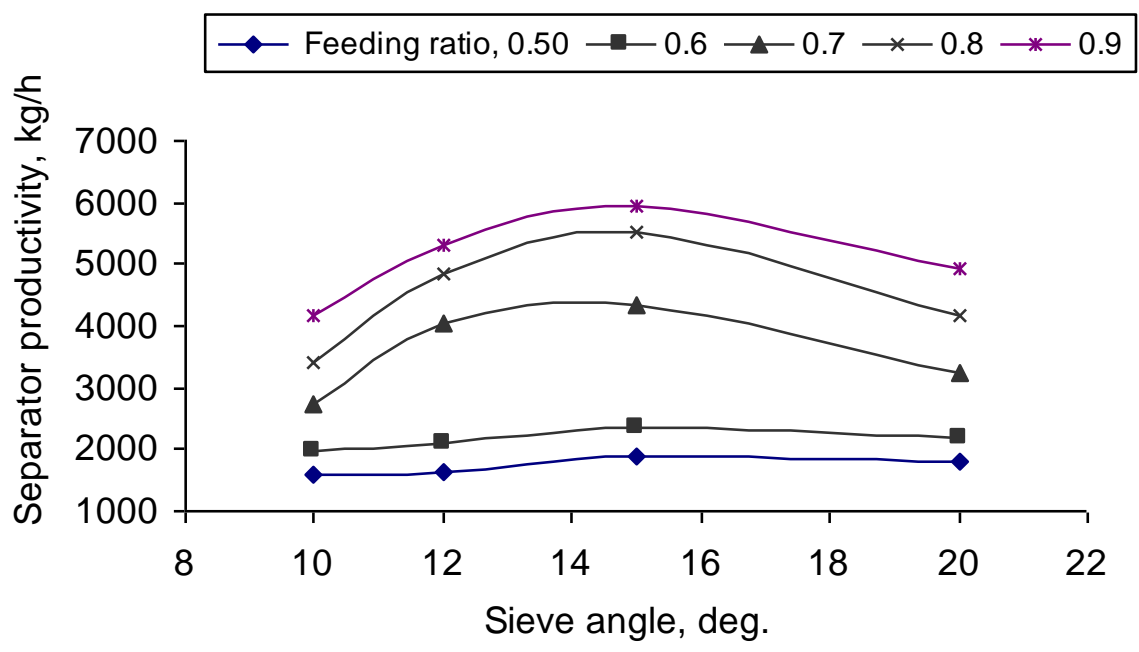

Fig. 4: Effect of sieve angle on the separator productivity at different feeding ratios (constant moisture content $14 \%$ )

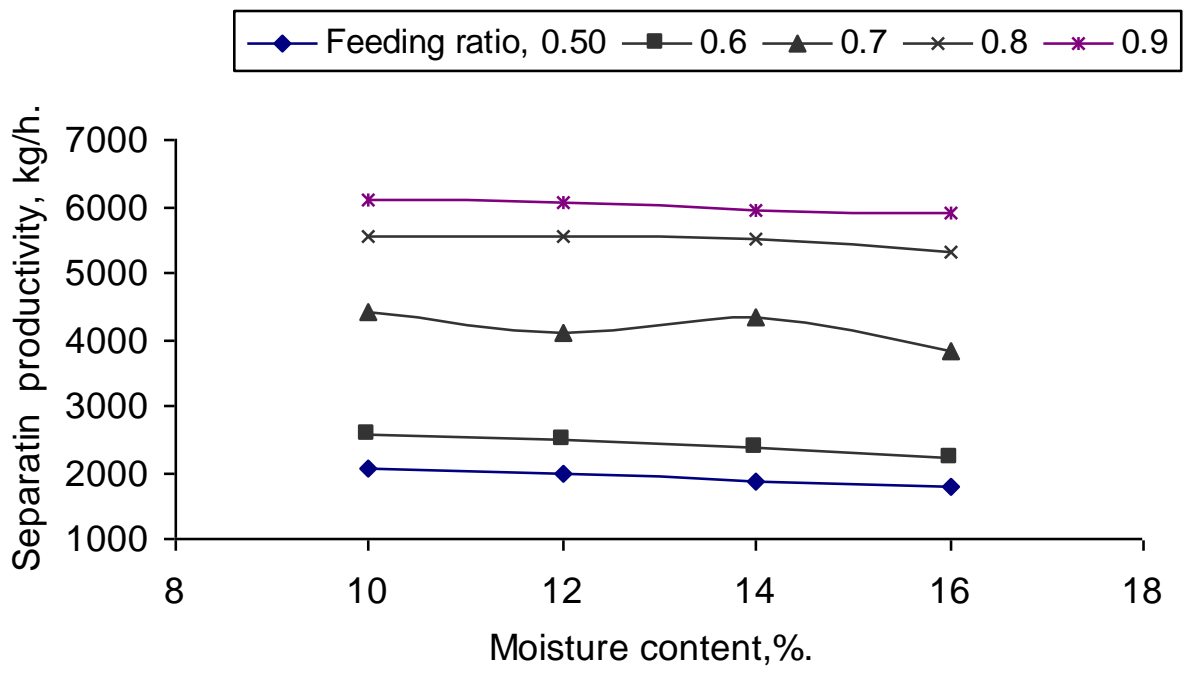

Fig. 5: Effect of paddy moisture content on the separator productivity at different feeding ratios (sieve angle, $15 \mathrm{deg}$.)

-Factors affecting separator crack percentage.

Representative crack percentage values versus both sieve angle and paddy moisture content are given through various feeding ratios in figs. 6 and 7. Concerning the effect of sieve angle on separator crack 
percentage, results in fig. 6 show that increasing sieve angle from 10 to 15 degrees, measured for various feeding ratios of $0.5,0.6,0.7,0.8$ and 0.9 , decreased separator crack percentage by $37.5,47.12,36.45$, 28.12 and $31.21 \%$ at constant paddy moisture content of $14 \%$. Any further increase in sieve angle from 15 up to 20 degrees separator crack percentage was increased by $18.36,25.80,22.78,13.20$, and $7.69 \%$ under the same previous conditions. Any increases or decrease in sieve angle more or less than $15 \mathrm{deg}$. Tends to increase crack percentage due to the non uniform movement of materials on the surface of sieves.

Considering the effect of paddy moisture content on separator crack percentage, obtained data in fig.7 show that increasing moisture content from 10 to $16 \%$, measured at various separator ratios of 0.5 , $0.6,0.7,0.8$ and 0.9 , decreased separator crack percentage by 21.66 , $26.76,15.55,11.60$ and $20.00 \%$ at constant sieve angle of 15 degree. The decrease in brown rice moisture content tends to increase crack percentage because dry grains are more sensitive to impact with each other.

As to the effect of feeding ratio on separator crack percentage, results in figs. 6 and 7 show that increasing feeding ratio from 0.5 to 0.9 increased separator crack percentage by $62.96 \%$ at constant paddy moisture content of $14 \%$ and constant sieve angle of 15 degree. This is due to the high density of materials on the sieve surface that increases pressure and impact forces between grains.

\section{- Factors affecting separator efficiency.}

The most critical factors affecting separator efficiency are sieve angle, paddy moisture content and feeding ratio in figs. 8 and 9

With regard to the effect of sieve angle on separator efficiency, results in fig. 8 show that increasing sieve angle from 10 to 15 degrees, measured for various feeding ratios of $0.5,0.6,0.7,0.8$ and 0.9 , increased separator efficiency by 16.01, 16.27, 37.01, 38.33 and 29.78 $\%$ at constant paddy moisture content of $14 \%$. Any further increase in sieve angle from 15 up to 20 degrees, separator efficiency was decreased by $3.84,7.02,24.53,24.47$ and $17.20 \%$ under the same previous conditions. Higher or lower values of sieve angle more or 
$\multimap-$ Feeding ratio, $0.50 \rightarrow 0.6 \multimap 0.7 \multimap 0.9 \rightarrow 0.9$

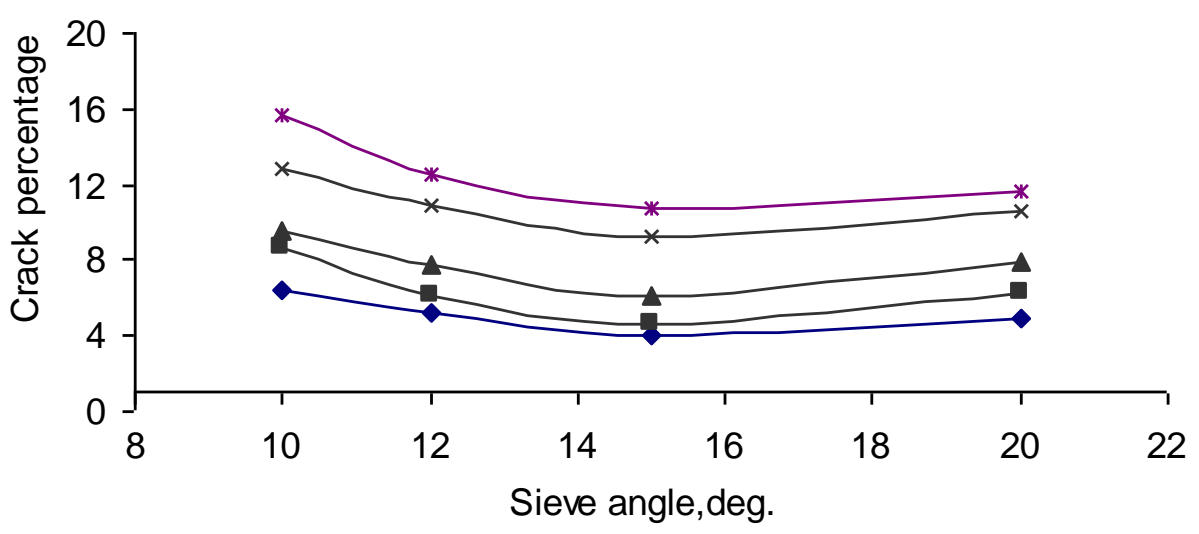

Fig. 6: Effect of sieve angle on the crack percentage at different feeding ratios (constant moisture content $14 \%$ )

$\multimap-$ Feeding ratio, $0.50 \rightarrow-0.6 \multimap 0.7 \rightarrow 0.8 \rightarrow-0.9$

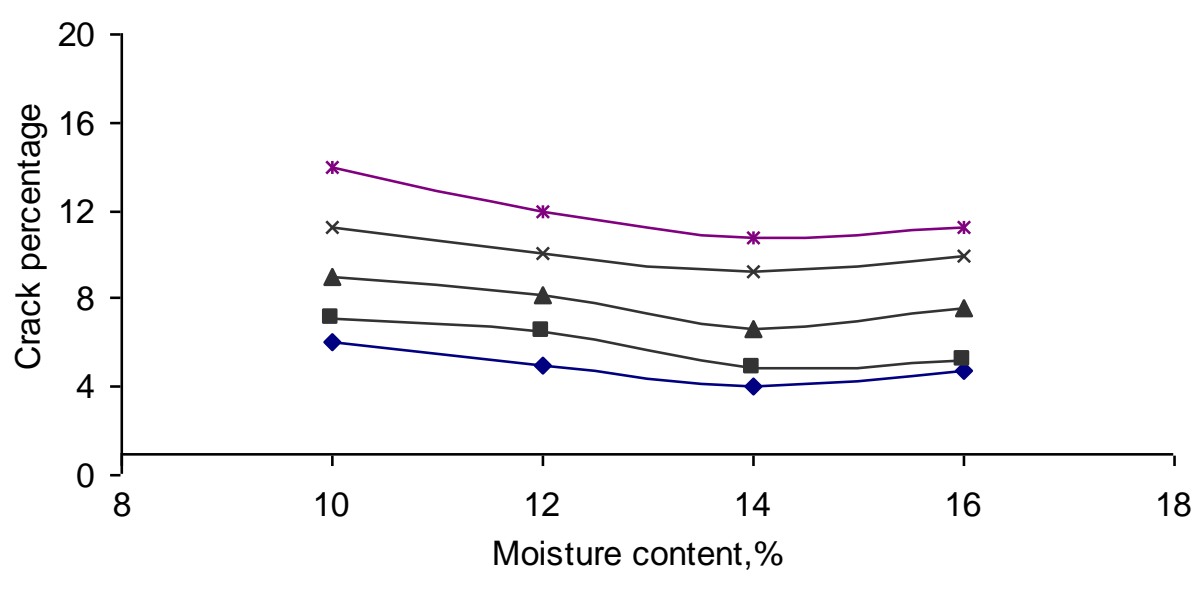

Fig. 7: Effect of paddy moisture content on the crack percentage at different feeding ratios (sieve angle, $15 \mathrm{deg}$.) 

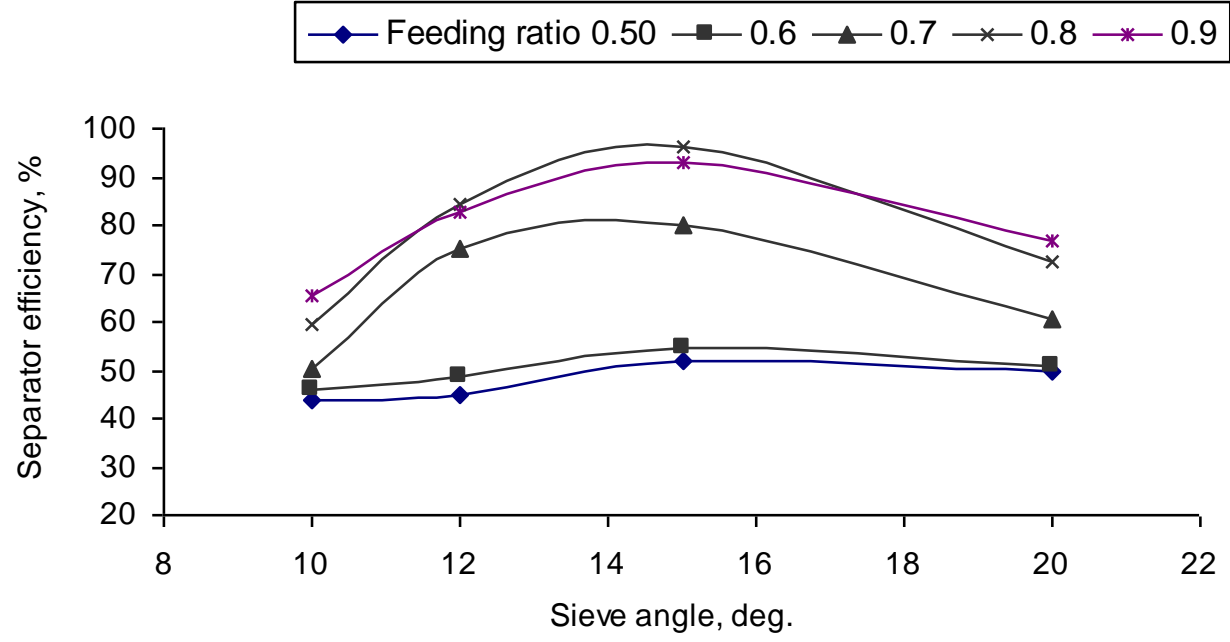

Fig. 8: Effect of sieve angle on the separating efficiency at different feeding ratios (constant moisture content $14 \%$ )
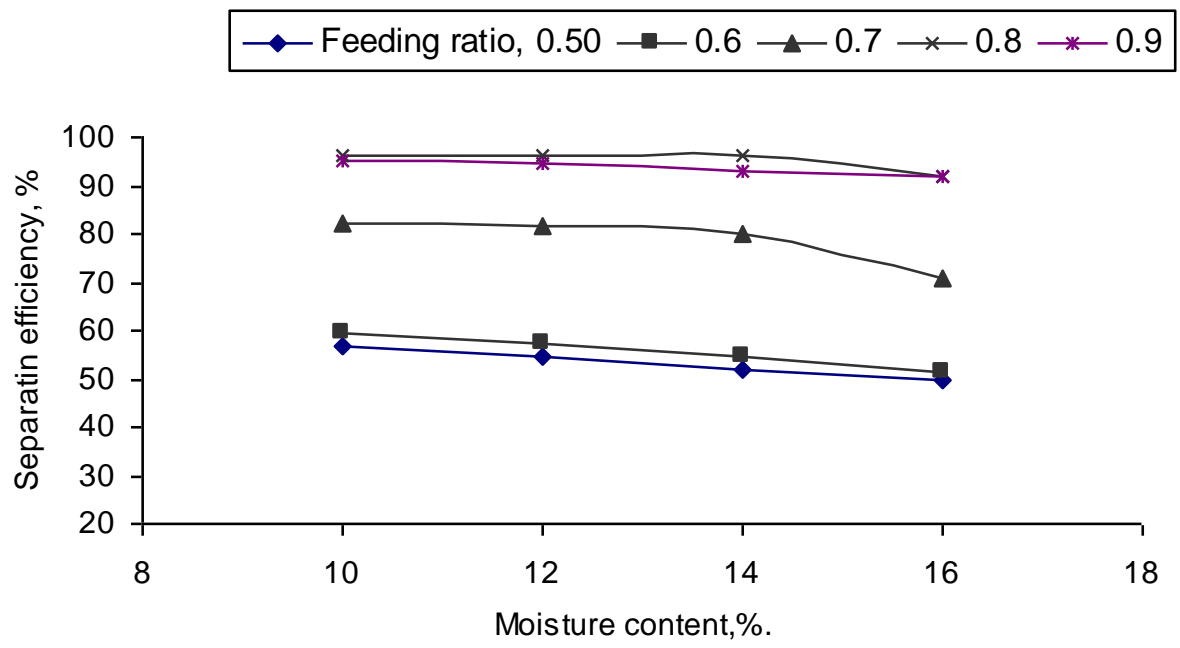

Fig. 9: Effect of paddy moisture content on the separating efficiency at different feeding ratios (sieve angle, $15 \mathrm{deg}$.)

less than $15 \mathrm{deg}$. decrease separator efficiency because of the decrease in separator productivity in both cases.

Mentioning to the effect of paddy moisture content on separator efficiency, obtained data in fig.9 show that increasing moisture 
content from 10 to $16 \%$, measured at various separator ratios of 0.5 , 0.6, 0.7, 0.8 and 0.9, decreased separator efficiency by 11.76, 13.54, $13.41,4.52$ and $3.15 \%$ at constant sieve angle of 15 degree. This attributed to the decrease in separator productivity by decreasing paddy moisture content.

As to the effect of feeding ratio on separator efficiency, results in figs. 8 and 9 show that increasing feeding ratio from 0.5 to 0.9 increased separator efficiency by $44.08 \%$ at constant paddy moisture content of $14 \%$ and constant sieve angle of 15 degree. Increasing feeding ratio increased separator productivity which in turn increased separator efficiency.

\section{- Factors affecting separator energy requirements.}

Separator energy requirements is more sensitive to different factors such as: sieve angle, paddy moisture content and feeding ratio.

Relating to the effect of sieve angle on separator energy requirements, results in fig. 10 show that increasing sieve angle from 10 to 15 degrees, measured for various feeding ratios of 0.5, 0.6, 0.7, 0.8 and 0.9 decreased separator energy requirements by 20.84, 20.06, 39.76, 43.70 and $37.17 \%$ at constant paddy moisture content of $14 \%$. Any further increase in sieve angle from 15 up to 20 degrees, separator energy requirements was un significantly increased by $1.34,3.79$, $8.65,23.25$ and $15.41 \%$ under the same previous conditions. Lower values of sieve angle less than $15 \mathrm{deg}$. increased energy due to the slow movement of paddy on the sieve surface especially with high feeding ratios while higher values of sieve angle more than $15 \mathrm{deg}$. also increased energy due to the decrease in separator productivity.

Regarding the effect of paddy moisture content on separator energy requirements, obtained data in fig. 11 show that increasing moisture content from 10 to $16 \%$, measured at various separator ratios of 0.5 , $0.6,0.7,0.8$ and 0.9 , increased separator energy requirements by $17.81,20.03,17.21,14.57$ and $13.99 \%$ at constant sieve angle of 15 degree. Increasing paddy moisture content, increased energy because of the elastic conditions of high moisture content material that lead to irregular motion. 
As to the effect of feeding ratio on separator energy requirements, results in figs. 1o and 11 show that increasing feeding ratio from 0.5 to 0.9 increased separator energy requirements by $64.87 \%$ at constant

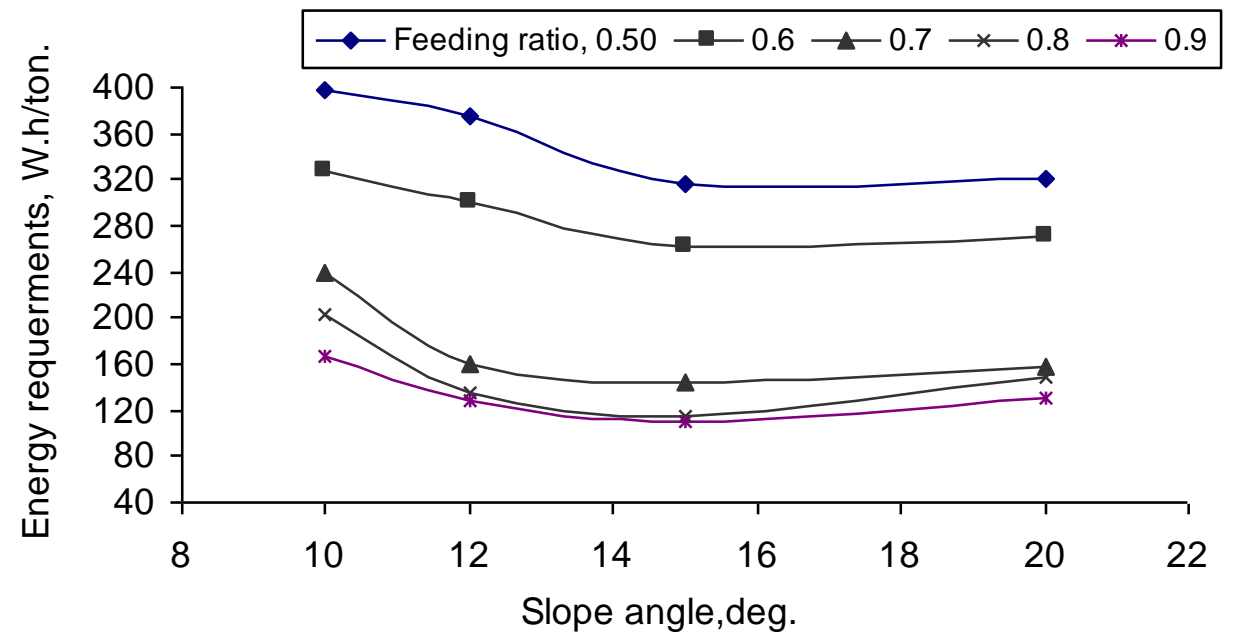

Fig. 10: Effect of sieve angle on the energy requirements at different feeding ratios (constant moisture content $14 \%$ )

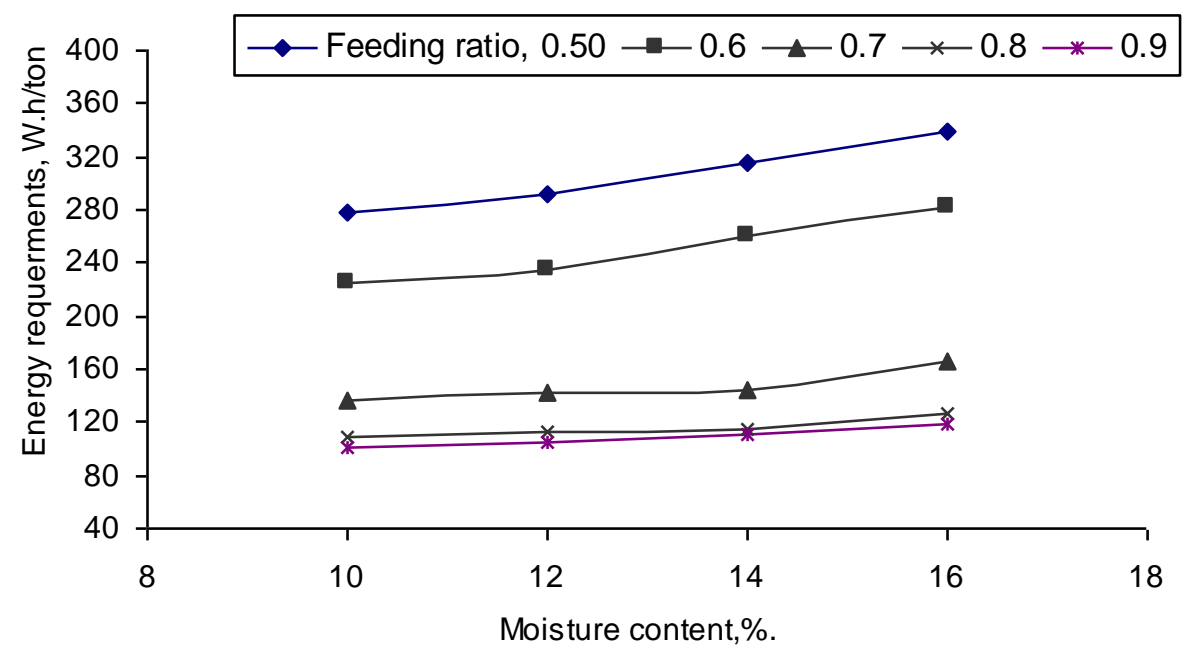

Fig. 11: Effect of paddy moisture content on the energy requirements at different feeding ratios (sieve angle, $15 \mathrm{deg}$.) 
paddy moisture content of $14 \%$ and constant sieve angle of 15 degree. The increase in feeding ratio, leads to an increase in material mass on sieve surface which in turn tends to increase energy.

\section{CONCLUSION}

Optimize paddy and rice separator variables is of great importance to minimize both crack and energy and maximize performance efficiency.

The theoretical and experimental results reveal that for obtaining high grade rice production, the following parameters must be adjusted as follows:

- Sieve speed of $0.5 \mathrm{~m} / \mathrm{s}$ (200rpm)

- Sieve angle of $15 \mathrm{deg}$.

-Paddy moisture content of $14 \%$

-Feeding ratio of 0.8 .

\section{REFERENCES}

Ahmed, S.F. (1988) Effect of control and management on the performance of grain sieve cleaners. Com. Sci. Dev. Res. 21 (254):98-106.

Ahmed, S.F.; M.M. Abbou El-Kheir and I. M. Abd El-Tawwab(1993). Development of an apparatus suitable for separating wheat products from stationary threshers. Misr J. Ag.Eng., 10 (1):6276.

Amin, E.E.(2003). Efect of some physical and mechanical properties on grading efficiency. Misr J. Ag. Eng.,20(4): 451-470.

Awady, M.N.; F. Yehia; M.T. Ebaid and E.M. Arif (2003). Development and theory of rice cleaner for reduced impurities and losses. Misr J. Ag. Eng., 20 (4): 53-68.

El-Raie, A.E. (1987). Propereties of shelled corn related to mechanical separation. Misr J. Ag. Eng., 4(1): 36-52.

El-Sahrigi, A.F.; S.F. Ahmed; M.A.Helmy; H.M.Sorour and S.S.Hanna (2004). Construction and development of a cleaning 
unit suitable for medicinal and aromatic seed crops. Misr J. Ag. Eng., 21 (4): 53-66.

Klenin,N. F. Popov and V.A. Sakon (1985). Agricultural machines. Theory of operation, computation of controlling parameters and the conditions of operation. Amerind publishing Co. PVT.Ltd., New Delhi.

Modi, B.S.(1972). Factors affecting the performance of apaddy separator. Unpnb. M. tech. Thesis, Dept. Agric. Eng. Indian Institute of technology, Kharagpur.

الملخص العربي - n

دراسات هندسية على أداء فراز الأرز

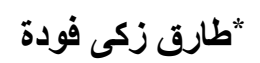

يعتبر محصسول الأرز مـن المحاصيل الهامـة في مصر للذا كـان مـن الضـروري الاهتمـام

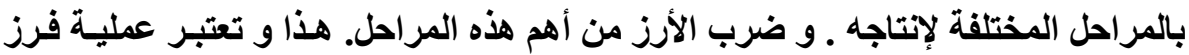

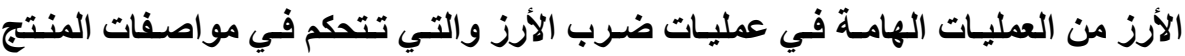

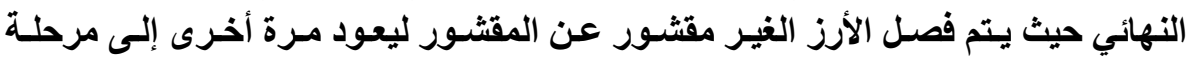

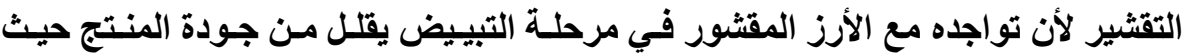

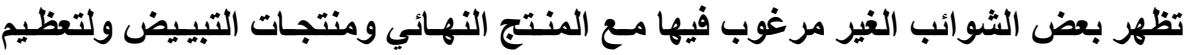

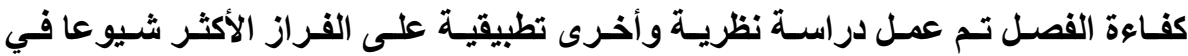

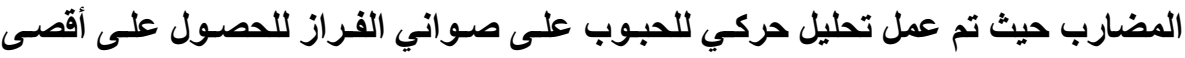

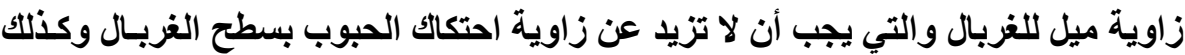

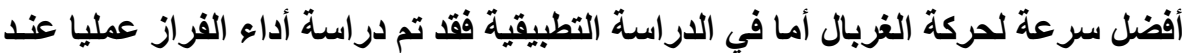

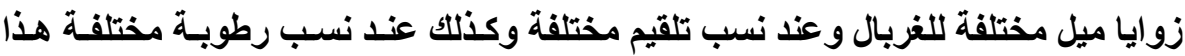

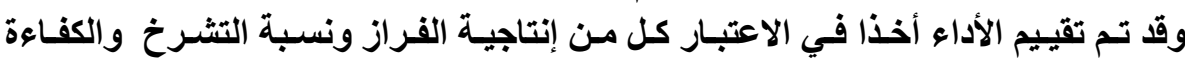

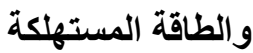

وقد أظهر التحليل الكينماتيكي أن زاوية ميل الغربال يجب أن تقل عن · ـ درجـة (أقل مـن

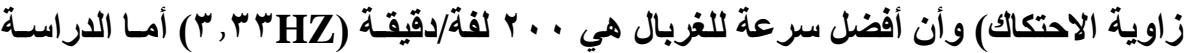

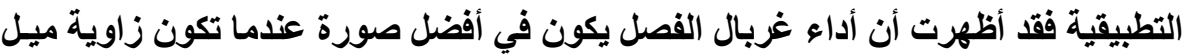

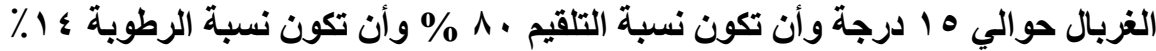

